\title{
SEAMEO Basic Education (SEA-BES): Common Core Regional Learning Standards (CCRLS) in Mathematics:
}

\author{
A Tool for Enhancing STEM Education
}

\author{
Pedro Montecillo, Jr.* \\ Training Program Division \\ Mathematics Education, \\ Specialist \\ SEAMEO RECSAM, \\ Penang, Malaysia \\ pedro@recsam.edu.my
}

\author{
Teh Kim Hong \\ Training Program Division \\ Mathematics Education, \\ Specialist \\ SEAMEO RECSAM, \\ Penang, Malaysia
}

\author{
Prof. Masami Isoda \\ Director CRICED \\ University of Tsukuba, Japan \\ Tsukuba, Japan
}

\begin{abstract}
Most countries in South East Asia came out among the last third in TIMSS 2011 and PISA 2012 in both mathematics, science and reading except Singapore who tops among all nations. The same performance standing appeared in 2015. Presently, there is no agreement on the scope, breadth, width and content of basic education among SEAMEO member countries. Its main purpose is to strengthen ASEAN collaboration on curriculum standards and learning assessment across different education system to effectively response to the changing global context. It can be used as an analytical tool to support future development of regional integrated curriculum necessary for ASEAN integration with emphasis on $21^{\text {st }}$ century skills. This common platform will promote in every member country the establishment of best practices to overcome differences in curriculum and performance. It will help to create in harmonizing curriculum provisions across countries, learning expectations and learning outcomes that will enable students to be competent, and subsequently contribute productively to their individual country and the region. Content analysis and mapping of the curriculum were done through series of workshops organized in RECSAM, Penang Malaysia and twice meeting of experts in the University of Tsukuba since $2015-2016$. The findings and the results will be highlighted and reported on how these documents will be use and accepted to all SEAMEO member countries.
\end{abstract}

Keywords-mathematics, basic education ASEAN countries, mathematics curriculum framework, mathematics learning outcomes and sustainable development.

\section{INTRODUCTION}

The goal of regional integration in the development of an 'ASEAN Community' provides the opportunity for the development of an educational policy framework for all SEAMEO Member countries in order to enhance access to educational opportunities, to support the development of quality basic education and to encourage regional mobility. Indeed the SEAMEO Education Agenda \#7 “Adopting a 21st Century Curriculum" states to pursue a radical reform through systematic analysis of knowledge, skills, and values needed to effectively respond to changing global contexts, particularly to the everincreasing complexity of the Southeast Asian economic, socio-cultural, and political environment, developing teacher imbued with ASEAN ideals in building ASEAN community within 20 years (20152035).

The $21^{\text {st }}$ century curriculum encompasses learning, literacy and life skills. Competent learners should be able to use tools such as language and technology to convey ideas and thoughts, can act autonomously based on rational decisions and ability to interact well with others in the community. In that context, learners will grow and develop with knowledge and skills that enable them to find jobs, being responsible, self-reliant and contributing to society.

OECD clarified the $21^{\text {st }}$ century skills by the terms of competency (OECD, 2005). It defined competency for successful life and well-functioning society. Societies are continuously changing for seeking success and welfare development. UNESCO sets the sustainable development goals (UNESCO, 2015) under the necessity of the development of every 
society as well as sustainability of social welfare. On this context, Mathematics and Science are necessary subjects in education for success in various fields as well as welfare in our life based on mutual understanding. Mathematics and science are the tools for overcoming the challenges of diversities in Southeast Asia through developing the competency for these competitiveness and understanding others for creating a harmonious society. capital, process skills need to be developed. Thirdly, knowledge of mathematics are for cultivating well qualified citizens.

Specifically it sought to answer the following questions;

1) What are the standards that are common ground to develop the fullest potential and capabilities to acquire competency in the $21^{\text {st }}$ century?

2) What are the standards that are presumed for competitiveness in this globalization era and understanding others in creating the ASEAN harmonious society under global citizenship?

\section{B. SEABES PROJECT FRAMEWORK}

SEABES Project was initiated in 2014 before the establishment of the 7 Priority Areas and to response for the SEAMEO college project for preparation of the ASEAN Community. The original conceptual

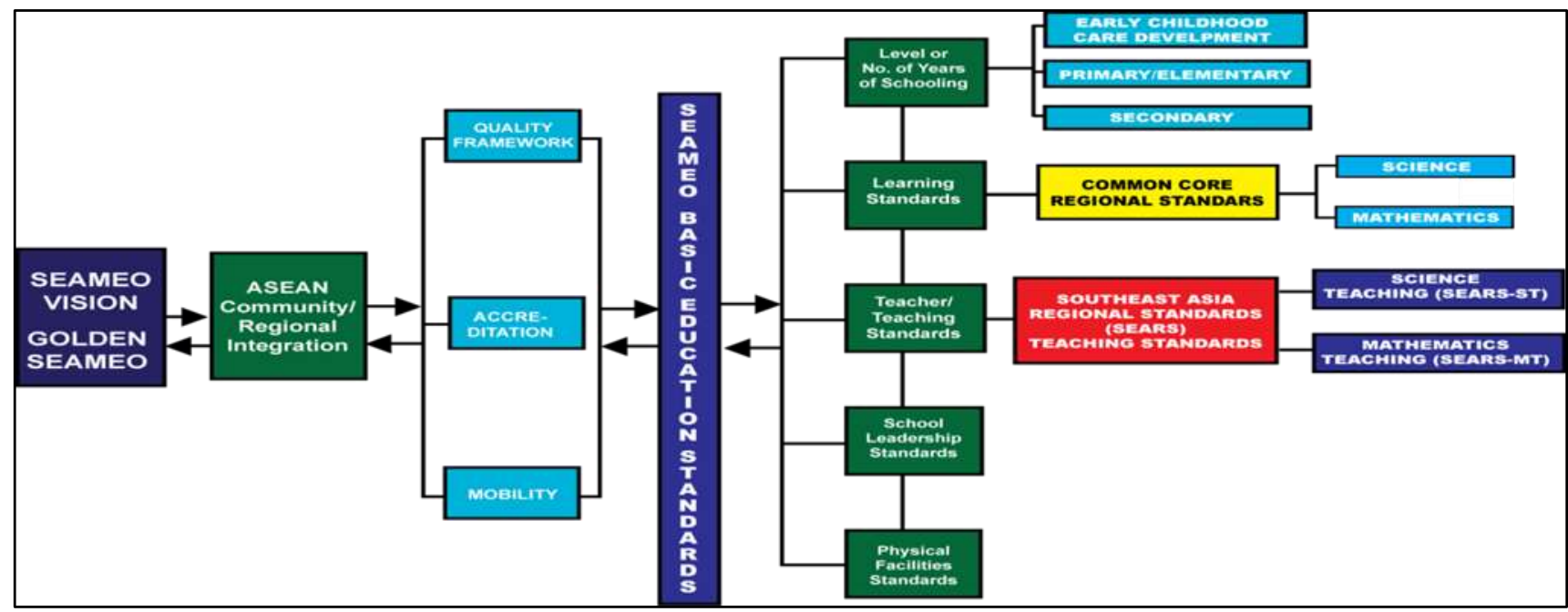

Fig. 1. shows the position of the CCRLS under the SEA-BES project framework

\section{A. PURPOSE AND SIGNIFICANCE OF THE PROJECT}

The purpose of the Common Core Regional Learning Standards (CCRLS) for Mathematics is to develop basic human characters, creative human capital, and well qualified citizens in Southeast Asia for a harmonious society. The purpose can be developed under three major components. Firstly, for cultivating basic human characters, values, attitudes and habits of mind. Values are basis for setting objectives of undertakings and making decisions for future directions. Attitudes are mind-sets for attempting to pursue endeavours. Habits of mind develop soft skills which are necessary for living harmoniously in the society. Secondly, for developing creative human framework is shown in Figure 1.

\section{METHODOLOGY TO DEVELOP CCRLS}

Fig. 2. shows the original flow process of the development of the common core regional learning standards in science and mathematics. 


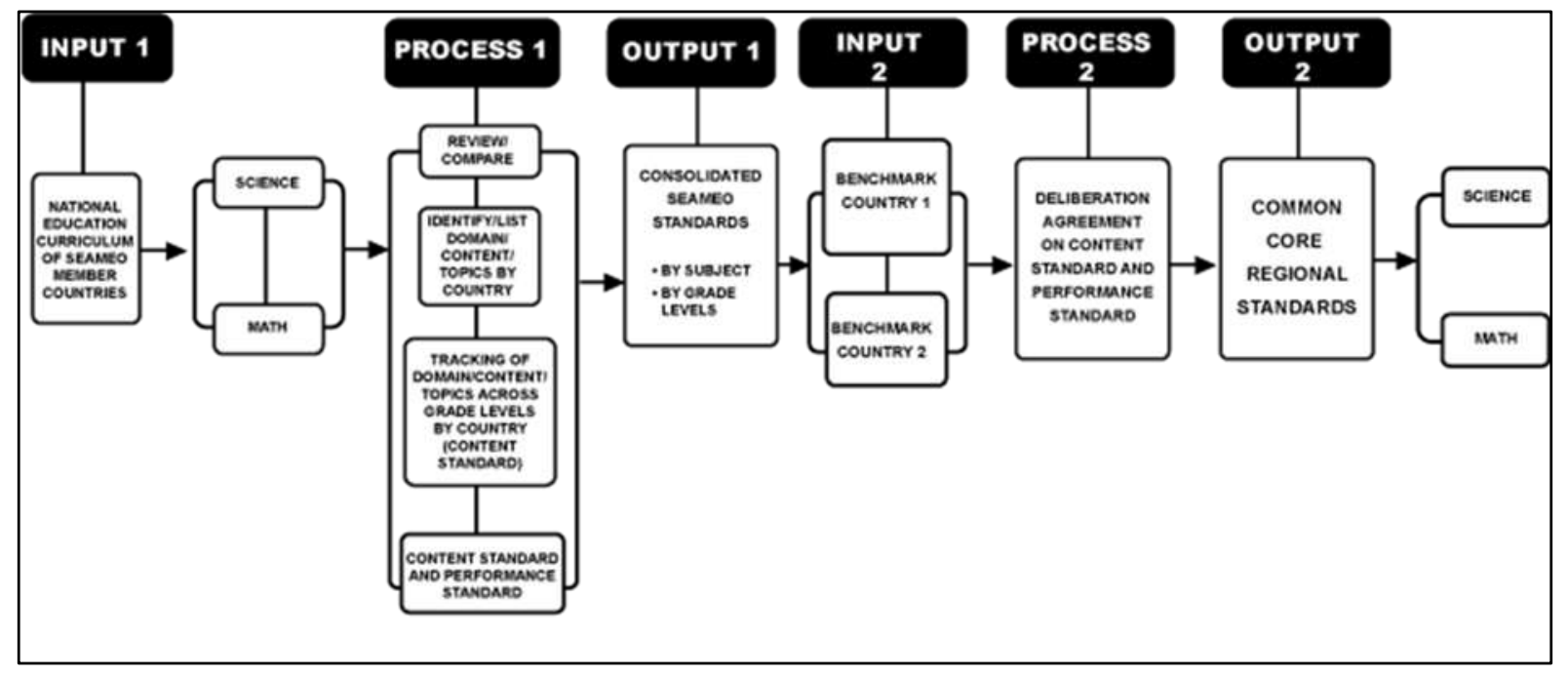

Fig. 2. Framework in developing the CCRLS in Science and Mathematics for SEA-BES (Mangao, D., Tahir, S., and Zakaria, M.J., 2015)

\section{LITERATURE REVIEW}

Mathematics has been recognized as a necessary literacy for citizenship and not only living economically but also to establish a society with fruitful arguments and creations for better living. It has been taught as a basic language for all academic subjects using visual and logical-symbolic representations. In this information society, mathematics has increased its role to establish $21^{\text {st }}$ century skills through reviewing mathematics as the science of patterns for future prediction and designing with big data which produces innovation not only for technology advancement but also for business model. Mathematics is an essential subject to establish common reasoning for sustainable development of society through viable argument in understanding each other and develop critical reasoning as the habits of mind. Mathematics should be learned as basis for all subjects. For clarifying the framework in CCRLS on mathematics and by knowing the role of mathematics education, the humanistic and philosophical natures of mathematics are confirmed as follows;

Humanistic nature of mathematics are explained by the attitudes of competitiveness and understanding of others by challenging mathematicians such as Blaise Pascal, Rene Descartes, Isaac Newton and Gottfried Wilhelm Leibniz. For example, if you read the letter from Pascal to Pierre de Fermat you recognize competitive attitude of Blaise Pascal to Fermat intelligence and seeking the way to be understood his Excellency of his finding on Pascal's Triangles. If we read the Pascal's pensee you recognize how Pascal's denies Descartes geometry using algebra from
The aspect of ancient Greece geometry. On the other hand, Descartes tried to overcome the difficulties of ancient geometry by algebra. If you read the letter from Descartes to Elisabeth, you recognize how Descartes appreciated and felt happy the Royal Highness Elisabeth used his ideas of algebra in geometry. Despite being a princess, Elisabeth had been continuously learning mathematics in her life.

Philosophical nature of mathematics can be explained on ontological and epistemological perspectives. On the ontological perspective, mathematics can be seen as a subject for universal understanding and common scientific language. Plato and Aristotle are usually compared on this perspective. Plato believe that the existence of the world of "idea" and mathematics is existed in the world of "idea" on Platonism. On this context, mathematical creation is usually explained by the word "discover" which means taking out the cover from which has already existed. At the moment of discovery, reasonable, harmony and beautifulness of mathematical system is usually felt. Aristotle tried to explain about reaching idea from the "material" to the "form". This explains that abstract mathematics can be understood with concrete materials using terms such as "modelling", "instruments", "embodiment", "metaphor" and "change representation". From both ontological perspectives, mathematics can be understandable and acquirable by everyone and if acquired, it serves as a common scientific language which is used to express in any subjects. Once representing the ideas using the shared common language, the world can be possibly perceived in the same view autonomously. 
On the epistemological perspective, mathematics can be developed through processes which are necessary to acquire mathematical values and ways of thinking. From this perspective, idealism and materialism are compared. On the context of Hegel, a member of German idealism, Imre Lakatos explained the development of mathematics through proof and refutation. On his context, mathematics is not a fixed but an expandable system that can be restructured through a process of dialectic in constructing viable arguments. Plato also used dialectic for reaching ideas with the examples of mathematics. The origin of dialectic is known as the origin of indirect proof. In education today, dialectic is a part of critical thinking for creation. Parallel perspectives for mathematical developments are given by George Polya and Hans Freudenthal. For the discovery of mathematics, Polya explained mathematical problem solving processes with mathematical ideas and mathematical ways of thinking in general. Freudenthal enhanced the activity to reorganize mathematics by the term mathematization.

Genetic epistemologist Jean Piaget established his theory for operations based on the various theories including Freudenthal discussion and explained mathematical development of operations by the term reflective abstraction. Reflection is also necessary activities for mathematization by Freudenthal. On materialism, under Vygotskyian perspective, intermediate tools such as language become the basis for reasoning in the mind. Under his theory, the high quality mathematical thinking can be developed depending on the high quality communication in mathematics classrooms. Dialectical-critical discussion should be enhanced in the mathematics class. From both epistemological perspectives, mathematics can be developed through the processes of communication, problem solving and mathematization which include reorganization of mathematics. Those processes are necessary to acquire mathematical values and ways of thinking through reflection.

\section{METHODOLOGY}

The following were the methodology used in gathering data;

1) Method used: Content analysis and participative inquiry.

2) A mapping of the curriculum was done through several workshops:

a) Eight (8) series of workshops in RECSAM, Penang Malaysia.

b) Four (4) regional seminars were organized in RECSAM (2) and University of Tsukuba, Japan (2) between 2014 and 2016.
3) The CCRLS were developed based on the strengths of the existing national education standards of the SEAMEO Member Countries.

4) The various activities undertaken in the development of the draft of working paper of CCRLS in Science and Mathematics include:

a) curriculum review and comparison of the national education curriculum of the seven SEAMEO Member Countries in Science and Mathematics, namely Brunei Darussalam, Cambodia, Indonesia, Malaysia, Philippines, Singapore and Thailand;

b) Identification of similarities and differences in terms of content/domain/topics/strand by country;

c) Tracking of content/domain/topics/strands across grade levels from the primary to secondary level; and consolidation of content standards and performance standards by subject and by grade levels from primary to secondary levels.

\section{Results AND RESEARCh PRESENTATION}

For cultivating well qualified citizens, content knowledge of mathematics are essential. Content of mathematics are usually divided by the set of mathematics. However, for developing human characters and creative human capitals, it should be developed through the mathematical processes. Values, attitudes and habits of mind are driving force to engage in mathematical processes. Thus, without involving human character formations with mathematical process skills, content knowledge of mathematics cannot be realised. The content is divided into three stages in CCRLS and every stage has four strands. Between the stages, the name of the strands are directly connected however, on the standard level, well connected. The name of strands for every key stages are as follows:

$\begin{array}{ll}\text { Key Stages } & \text { Strands } \\ \text { Key Stage 1 } & \text { Numbers and Operations } \\ & \text { Quantity and Measurement } \\ & \text { Shapes, Figures and Solids } \\ & \text { Pattern \& Data Representations } \\ & \text { Mathematical-Process Humanity } \\ & \text { Strands } \\ \text { Key Stage 2 } & \text { Extension of Numbers and Operations } \\ & \text { Measurement and Relations } \\ & \text { Plane Figures \& Space Solids } \\ & \text { Data Handling and Graphs } \\ & \text { Mathematical-Process Humanity } \\ & \text { Strands }\end{array}$


Key Stage 3 Numbers and Algebra

Relations and Functions

Space and Geometry

Statistics and Probability

Mathematical-Process Humanity

Strands

Presentation of the SEABES CCRLS:

The content are divided into 3 key stages. Each key stage has four content strands and one mathematical process-humanity strand. The content strands describe the content standards. The mathematical processhumanity strands describe the elements covered under mathematical thinking and process component, and values, attitudes and habits of human character component. The descriptions of every standard under the process-humanity strands are commonly discussed across different content strands within the same key stage.

Framework for CCRLS in Mathematics as in figure 3 are developed under the three components and the discussion of humanistic and philosophical nature of mathematics. The framework also provides the concrete ideas of mathematics learning on the above aims.

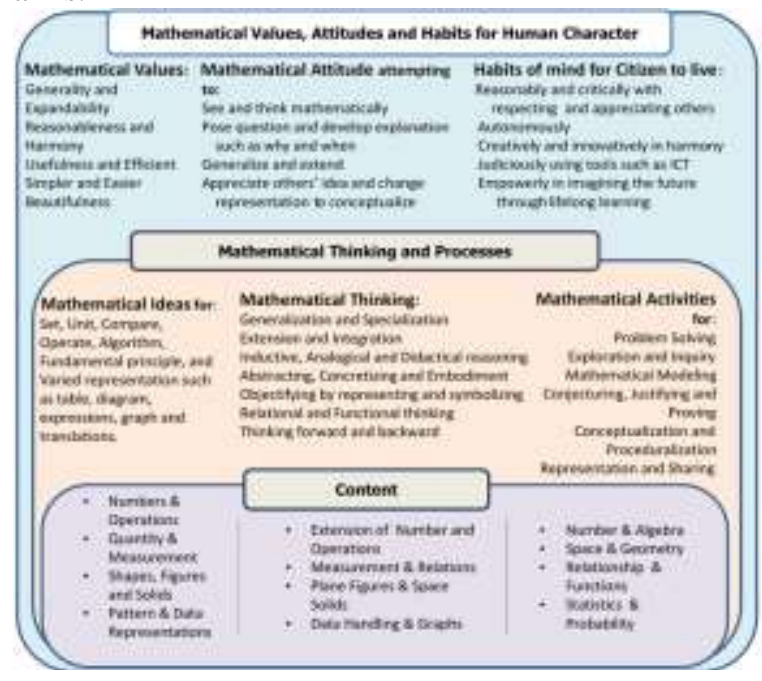

Fig. 3. CCRLS Framework for Mathematics

Three components in Figure 4 should be embedded in every key stages as standards for the content of teaching. "Mathematical values, attitudes, habits for human character" component and "Mathematical thinking and processes" component cannot exist without "Content" component. The first two components can be taught through teaching with the content.

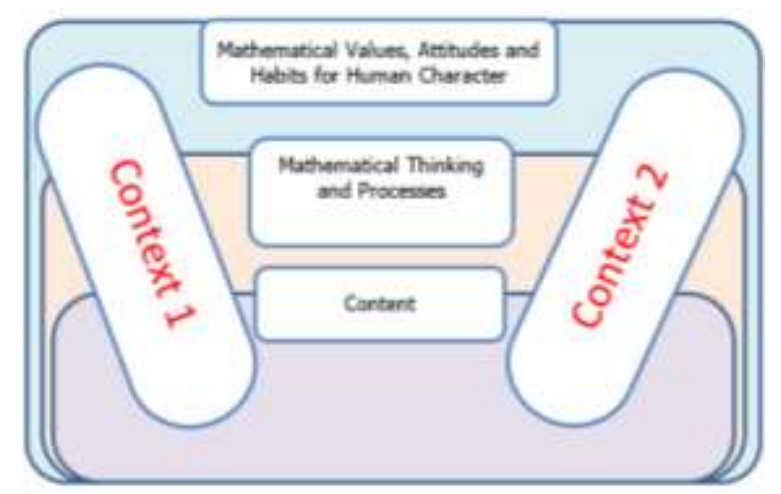

Fig. 4. Interlinking of the three components with the context

A. An Example of Documents: How Key stage 1 is interrelated to Stage 2 and 3 together with the Humanity Process Standards

\section{1) Key Stage 1}

Key Stage 1 (KS1) serves as the foundation of knowledge covering the basic facts and skills developed through simple hands-on activities, manipulation of concrete objects, pictorial and symbolic representations. This stage focuses on arousing interest, enjoyment and curiosity in the subject through exploration of pattern, characterization, identification and describing shapes, performing the four fundamental operations, identify its algorithm, and understanding basic mathematical concept and skills experienced in daily life.

\section{a) Strands: Pattern and Data Representations}

Exploration of patterns and features are also considered to represent the data structure in our life with pictographs and bar graphs. Patterns and features produce meaning of data and represent mathematical information. Patterns are represented by diagrams and mathematical sentences which are also used for communication in identifying and classifying situations to produce meaningful interpretations.

\section{b) Topic: Collecting data and represent the structure}

Standards: Representing a data structure by using bar graph to predict the future of communities.

1) Understand how to draw bar graph from table using data categories and sort the graph for showing its structure

2) Appreciate ways of presenting data such as using tables, pictograms and bar graphs with sorting for predicting their future communities

3) Appreciate the using of data for making decision 


\section{c) Strand: Mathematical Process - Humanity}

Enjoyable mathematical activities are designed to bridge the standards in different strands. Ability to select simple, general and reasonable ideas enable effective future learning. Application of number sense provides facility for preparing sustainable life. At initial stage, concrete model manipulation is enjoyable, however drawing diagram is most necessary for explaining complicated situations by using simple representation.

Standards: Promoting creative and global citizenship for sustainable development of neighborhood using mathematics

1) Utilizing the notebooks and journal books to record and find good ideas and share with others

2) Preparing and presenting ideas using posters to promote good practices in neighborhood

3) Listening to other ideas and asking questions for better creation

4) Utilizing information, properties and models as basis for reasoning

5) Utilizing practical arts and outdoor studies to investigate local issues for improving welfare of life

\section{2) Key Stage 2}

Key Stage 2 (KS2) can be learned based on the key stage 1 . This stage provides the extension of numbers, measurement and relations, plane figures and solid figures and data handling and graphs. This stage enable to extend four operations to daily use of numbers such as decimal and fraction and allows the use of mathematical terminologies, performing investigations and establish the ground for analyzing, evaluating and creating their life. Appreciating the beauty of the structure of mathematics will enable them to enjoy and sustain their learning which provides basis for key stage 3 .

\section{a) Strand: Data Handling and Graphs}

The process of simple data handling is introduced through data representation such as using table, bar graph, line graph, bar chart and pie chart. Graphs are utilized depending on the qualitative and quantitative data used such as bar graph is for distinguishing and counting in every category. Histogram is necessary for interpreting the data representation of social study and science, and is also used as a special type of bar graph. Average is introduced based on the idea of ratio for making the dispersion of bar chart even, and used for summarizing and comparing data on a table. Problemplan-data analysis-Conclusion (PPDAC) cycles are experienced through the process of data handling by using those data representation skills. Those skills are necessary for learning of sustainable development.

b) Topic: Using graphs in PPDAC ${ }^{1}$ cycle
appropriately

Standards: Identifying appropriate graphs for data handling in PPDAC cycle

- Critique a situation and discuss the expectation before taking data for proper clarification of the objective

- Plan the survey for the expectation

- Take the data based on the objective of the situation

- Use appropriate graphical representation which is most suitable for the objective

- Appreciate the use of graphs before making the conclusion

c) Strand: Mathematical Processes - Humanity

As a follow up of key stage 1, activities are designed to enable an appreciation of knowledge and skills learned and the ways of learning such as applying knowledge of number sense to solve daily problems. Mathematical processes such as communication, reasoning are used to provide explanation for mathematical problems and modelling. The ability to connect and reason mathematical ideas would trigger an excitement among learners. Discussion of misconceptions are usually enjoyable and challenging. Mathematics learning usually begins from situations at key stage 1 . In key stage 2, the development of mathematics is possible through the discussions for the extension of the forms. Appreciation of ideas and representations learned become part of the enjoyable activities. Through the consistent use of representations such as diagrams, application of learning become meaningful.

Standards: Experiencing PPDaC (Problem-Plan-Data analysis-Conclusion) cycle and modelling cycle in simple projects in their life

- Understand the problem of context

- Plan appropriate strategies to solve the problem

- Gather data and analyze using appropriate methods and tools

- Draw conclusion with justification based on data analysis

1) Key Stage 3

Key Stage 3 (KS3) can be learned based on the key stage 2. This stage learns number and algebra ${ }^{1}$, 
relations and function, space and geometry and statistics and probability. Symbolic representations allows dealing abstract ideas and concepts that enhances critical thinking, creative thinking through the application of knowledge. Understanding and using of concepts and principles in this stage through participating discussions, dialogue, and arguments enable them to participate in contemporary societal, economic, technological, political, environmental and mathematical issues. This stage is the basis for the creation of better future with predictions. It bridges the further mathematics learning in various job demands.

\section{a) Strands: Statistics and Probability}

Data handling are extended to explore the dispersion of histogram with mean, median, mode and range. Exploratory data analysis (EDA) attempting to represent and visualize the structure from the given data using Information Communication and Technology (ICT) is enhanced. Using skills of statistics and probability make problem solving in situations possible. Analyzing and identifying the trends in situations for making decisions are necessary such as issues for sustainable living.

\section{b) Topic: Exploring statistics with sampling}

Standards: Exploring sampling with the understanding of randomness

- Discuss the hidden hypothesis behind sample and population ratio,

- Use randomness to explain sampling

- Appreciate data sampling in a situation with sustainable development

\section{c) Strand: Mathematical Processes - Humanity}

Enhance the critical argument in mathematics on communication with others beyond stage 2 . Proposed challenging activities to promote metacognitive thinking at different level of arguments to make sense of mathematics. Translating real life activities into mathematical models and solving problems using appropriate strategies are emphasized in functional situations. The process of doing mathematical activities involve patience that develop perseverance in learners and take responsibility of one's own learning. At this stage, the habitual practice of selflearning will eventually develop confidence, thus, opportunity for challenges to extend mathematics and the ability to plan sequence of future learning are also enhanced.
Standards: Designing models for sustainability using mathematics ${ }^{1}$

- Discuss and utilize probabilities in their life such as weather forecasting for planning

- Design cost saving life style models through comparison of data such as cost of electricity, water consumption, and survey

- Plan emergency evacuation such as heavy raining and landslide where the calculations on the amount of water in barrel per minute exceeds the maximum standards

- Forecast the future with mathematics

\section{CONCLUSIONS AND RECOMMENDATIONS}

Standards found in every stages are useful for every country to engage in their own activity on a) to f) especially for considering the experiment and challenges for every country's curriculum reform.

The SEAMEO Basic Education Standards initiative would support SEAMEO Member countries in the following respects:

a) to use it as an analytical tool to support future development of regional integrated curriculum necessary for ASEAN integration with emphasis on $21^{\text {st }}$ century skills;

b) to strengthen ASEAN collaboration on curriculum standards and learning assessment across different educational systems to effectively respond to the changing global context and complexity of ASEAN ;

c) to promote in every member country the establishment of best practices to overcome differences in curriculum;

d) to produce systematic discussion process for the establishment of the regional integrated curriculum and assessment;

e) to use as a platform for curriculum development and professional development for all stakeholders developing teachers imbued with ASEAN ideals in building ASEAN community;

f) to serve as a platform for assessment such as the Southeast Asia Primary Learning Metrics (SEAPLM).

\section{REFERENCES}

Books:

[1] Aristotle . Metaphysics. Penguin. (1991).

[2] Dossey, J. A. The Nature of Mathematics: Its role and its influence. (1992). 
[3] Erik-JanBos Princess Elizabeth of Bohemia and Descartes' letters (1650- 1665) Historia Mathematica 37 (3), 485-502. (2010).

[4] Freudenthal, H., Mathematics as an Educational Task, Dordrecht: Reidel Publ. Company. (1973).

[5] Hegel, G.W.F., Di Giovanni, G. The Science of Logic, Cambridge: Cambridge University Press. (2015).

[6] In Grouws, D. A. (Ed) Handbook of Research on Mathematics Teaching and Learning (pp.39-48). New York: Macmilian.

[7] Isoda, M., Katagiri, S; coordinacion de Roberto Araya, traduccion dAlexis Jeldrez 2a ed[Santiago de Chile]: Ciae, Centro de Investigacion Avanzada en Educacion, Universidad de Chile. (2016).

[8] Isoda, M., Katagiri, S., Mathematical Thinking: How to Develop it in the Classroom, New Jersey: World Scientific. (2012).

[9] Isoda, M. Mathematization for Mathematics Education: An extension of the theory of Hans Freudenthal applying the representation theory of Masami Isoda with demonstration of levels of function up to calculus

(Written in Japanese). Tokyo: Kyoritsu Pub. (2015).

[10] Kilpatrick, J., Swafford, J., Findell, B. Adding it up: Helping Children Learn Mathematics, Washington, DC: National Academy Press(2012)

[11] Lakatos, I. Proofs and Refutations: the Logic of Mathematical Discovery, Cambridge: Cambridge University Press, 1976 Beth, E.W., (1976).

[12] Piaget, J.,Mays, W . Mathematical Epistemology and Psychology, Dordrecht: Springer. (1974).

[13] Lakoff G., \& Nunez R.E., , Where Mathematics Comes From: How the Embodied Mind Brings Mathematics Into Being, New York, NY Basic Books. (2001).

[14] Marsigit H., Research on the Role of Kant's Theory of Knowledge in Setting Up the Epistemological Foundation of Mathematics. (2007). retrieved from https://www.academia.edu/2229642/Research_on_the_Role _of_Kants_Theory_of_Knowledge_in_Setting_Up_the_Epis temological_Foundation_of_Mathematics on 8 October 2017

[15] Polya, G., How To Solve It: A New Aspect of Mathematical Method, Princeton, N.J., Princeton University Press. (1945).

[16] Piaget, J. \& Beth E.W., Mathematical Epistemology and Psychology, Dordrecht: Springer Netherlands. (1974).

[17] Plato, translated by W.R.M. Lamb. Plato: Laches, Protagoras, Meno and Euthydemus. London: Heinemann. (1924)

[18] Tall D. , How Humans Learn to Think Mathematically : Exploring the Three Worlds of Mathematics, Cambridge : Cambridge University Press. (2013).

[19] Vygotsky, L.S., , Thought and Language, New York : Wiles(1961)

Web:

[20] Blaise Pascal Letter from Pascal to Fermat, Wednesday, 29 July 1654" Extracted from http://cerebro.xu.edu/math/Sources/Pascal/Sources/pasfer.pd f on July $\quad 18,2017$

[21] Blaise Pascal Pensees, Extracted from http://www.ntslibrary.com/PDF\%20Books/Blaise\%20Pascal \%20Pensees.pdf on July 18, 2017

[22] United Nations. Sustainable Development Goals, Retrieved from

(2015)

http://www.un.org/sustainabledevelopment/news/communic ations- material/ on July 18, 2017

[23] OECD The Definition and Selection of Key Competency, (2005) Retrieved from https://www.oecd.org/pisa/35070367.pdf on July 18, 2017

\section{Curriculum Documents:}

[24] Common Core State Standards for Mathematics (2002) Retrieved from http://www.corestandards.org/wpcontent/uploads/Math_Standards1.pdf on 8 October 2017
[25] Executive Summary Principles and Standards for School Mathematics (2000) Retrieved fromhttps://www.nctm.org/uploadedFiles/Standards_and_Po sitions/PSSM_ExecutiveSummary.pdf on 8 October, 2017

[26] Isoda, M. English Translation of Japanese Curriculum Standards for Elementary School Mathematics: Elementary School Teaching Guide for the Japanese Course of Study: Mathematics (Grade 1-6). (2010). retrived from http://www.criced.tsukuba.ac.jp/math/apec/ICME12/Lesson _Study_set/in dex1.htm on 18 July, 2017.

[27] Isoda, M. Junior High School Teaching Guide for Junior High the Japanese Course of Study: Mathematics (Grade 7-9). (2010). retrived from http://www.criced.tsukuba.ac.jp/math/apec/ICME12/Lesson _Study_set/in dex1.htm, on 18 July, 2017.

[28] The Victorian Curriculum Mapped to the Australian Curriculum. (2016). Retreived from http://cdn.3plearning.com/wp content/blogs.dir/5/files/2016/08/AUS_AlignmentMath_VI C_201 6_WebV.pdf on 8 October 2017 Journal Documents:

[29] Bernoulli, J. Problema novum ad cujus solutionem Mathematici invitantur." Acta Eruditorum, 18: 269. (1696). 